\title{
THE STRUCTURE AND PROPERTIES OF REACTIVELY BONDED THICK FILM GOLD CONDUCTORS
}

\author{
M. V. COLEMAN and G. E. GURNETT \\ Standard Telecommunication Laboratories Ltd., London Road, Harlow, England
}

(Received October 20, 1977)

\begin{abstract}
The properties of reactively bonded gold conductors have been compared with a fritted gold conductor (DuPont 9260). Several different additives in the gold conductors were examined, including copper/copper oxide; copper plus cadium/germanium and copper cadium and bismuth.

The adhesion strength of all the conductors was found to be superior to the fritted standard, but the electrical conductivity did not appear to be improved. These materials thus offer advantages where stronger adhesion is required or possibly, where the interface between conductor and substrate needs to be well-defined.
\end{abstract}

\section{INTRODUCTION}

In the fired condition conventional thick film conductors consist of a metallic phase and between 1 and 5 percent by weight of a glass frit. The conductor adheres to the substrate, generally a debased (96\%) alumina, through the formation of a glassy layer, which keys both chemically and mechanically to the substrate. The layer is keyed to the conductor by glassy fibres, with rivet shaped heads, penetrating between the sintered mass of conducting particles. ${ }^{1}$ The newer type of reactively bonded conductor (sometimes referred to as fritless or molecular bonded conductor) does not contain a glass frit and adhesion is thought to occur through the formation of a crystalline compound at the surface of the substrate. The conductor in the fired state contains less than $1 \%$ of a bond-forming material and since a glass phase is not present, the conductor top surface should be more suitable for wire bonding, chip attach etc (i.e. there can be no penetration of glass to the surface). The absence of a glass phase should increase film conductivity, important for microwave applications, and a further advantage is that high (99.5\%) alumina substrates can be used.

Seven reactively bonded gold conductors were chosen for investigation, using Du Pont 9260 as a typical fritted conductor for comparison.

\section{COMPOSITION}

The major constituents, other than gold, of both unfired and fired samples of the conductors were identified using a mass spectrometer, and the amounts of copper and cadmium were determined by Atomic Absorption Spectroscopy ${ }^{2}$, Table I. The conductors can be considered as belonging to three categories: (a) those containing additives of copper/copper oxide only e.g. E06990 and C5700

(b) those containing copper and cadium or germanium (oxides) e.g. S4399, DP9500 and ESL 8880.

(c) those containing at least copper, cadmium and bismuth (oxides) e.g. EMCA 3264 and T2888 Categories (a) and (b) may be described as reactively bonded i.e. the adhesion is primarily with the alumina of the substrate and (c) may be described as mixed bonded i.e. there is adhesion with the alumina and also with glasses formed at the alumina surface with the minority constituents in the substrate.

The gold powders from the dried inks were examined using a Scanning Electron Microscope and were found to consist of two distinct types of particle; hexagonal platelets $2 \mu \mathrm{m}$ to $6 \mu \mathrm{m}$ diameter and a few tenths of a micron thick, and small spherical particles $0.2 \mu \mathrm{m}$ to $0.5 \mu \mathrm{m}$ diameter. The EO 6690 and C5700, as well as the fritted material DP 9260 contained mainly spherical particles, the others contained mixtures of platelets and small spherical particles.

\section{PHYSICAL AND ELECTRICAL PROPERTIES}

Each of the conductors was printed on to $96 \%$ alumina (Alsimag 614) substrates and fired through the manufacturer's optimum profile. Surface topology 
TABLE I

Composition and physical properties of gold conductors

\begin{tabular}{|c|c|c|c|c|c|c|c|c|c|c|c|}
\hline \multirow[b]{3}{*}{ Source } & \multirow[b]{3}{*}{ Ref. } & \multirow{3}{*}{$\begin{array}{l}\text { Major } \\
\text { Elements }\end{array}$} & \multirow{2}{*}{\multicolumn{2}{|c|}{$\%$ Composition }} & \multirow{3}{*}{$\begin{array}{l}\text { Thickness } \\
(\mu \mathrm{m})\end{array}$} & \multirow{3}{*}{$\begin{array}{l}R_{a} \\
(\mu \mathrm{m})\end{array}$} & \multirow{3}{*}{$\begin{array}{l}\text { Sheet R } \\
\mathrm{m} \Omega / \square\end{array}$} & \multirow{3}{*}{$\begin{array}{l}\text { Bulk R } \\
\mu \Omega . c m\end{array}$} & \multicolumn{3}{|c|}{$\begin{array}{l}\text { Adhesion strength in } \\
\mathrm{kgf} \text { of } 2.5 \mathrm{~mm} \text { pads }\end{array}$} \\
\hline & & & & & & & & & Alsimag & Coor & A \& \\
\hline & & & $\mathrm{Cu}$ & $\mathrm{Cd}$ & & & & & ADS614 & AD995 & 974 \\
\hline Cermalloy & S4399 & $\mathrm{Cu}, \mathrm{Ge}$ & 0.32 & - & 7.8 & 0.55 & 4.36 & 3.4 & 2.45 & 2.60 & 1.50 \\
\hline Du Pont & 9500 & $\mathrm{Cu}, \mathrm{Cd}$ & 0.83 & 0.18 & 9.2 & 0.52 & 4.54 & 4.2 & 3.98 & 4.94 & 1.45 \\
\hline E-O & E06990 & $\mathrm{Cu}, \mathrm{Cd}$ & 0.70 & 0.34 & 7.1 & 0.25 & 5.18 & 3.7 & 3.96 & 3.77 & 1.34 \\
\hline EMCA & 3264 & $\mathrm{Cu}, \mathrm{Cd}, \mathrm{Bi}$ & 0.70 & 1.23 & 9.1 & 1.60 & 5.09 & 5.2 & 2.03 & 1.83 & 1.42 \\
\hline Englehard & T2888 & $\mathrm{Cu}, \mathrm{Cd}, \mathrm{Bi}$ & 0.62 & 0.50 & 8.5 & 0.75 & 4.45 & 3.8 & 3.35 & 3.70 & 2.79 \\
\hline ESL & 8880 & $\mathrm{Cu}, \mathrm{Cd}$ & 0.49 & 0.30 & 9.8 & 0.70 & 3.38 & 3.3 & 3.53 & 3.13 & 1.07 \\
\hline Plessey & C5700 & $\mathrm{Cu}$ & 0.67 & - & 11.6 & 0.65 & 3.90 & 4.6 & 3.38 & 3.76 & 2.32 \\
\hline Du Pont & 9260 & $\mathrm{~Pb}, \mathrm{Si}$ & - & - & 7.7 & 0.75 & 4.66 & 3.6 & 1.26 & 0.78 & 1.11 \\
\hline
\end{tabular}

measurements were made on both Talysurf and Surfometer machines across a conductor meander track on the substrates. The $R_{a}$ value, which measured surface roughness, and the average conductor thicknesses were determined (see Table I). The surface of the EO 6990 conductor is significantly smoother than the other conductors, and the EMCA 3264 conductor is much rougher (Note that the recommended surface smoothness for wire bonding is $\left.\mathrm{R}_{\mathrm{a}}<0.07 \mu \mathrm{m}\right)$.

The electrical resistance of the meander track was measured by a 4-probe method. The effective resistivity (in ohm/D) and bulk resistivity were determined (see Table I). The bulk resistivity for gold at room temperature is $\sim 2.4 \mu \Omega \mathrm{cm}$ and the standard (fritted) DP 9260 is a factor of $\sim 1.5$ up on this value but is similar to the reactively bonded golds with the lowest resistivities. The bulk resistivity is therefore dependent upon the gold porosity of the bulk film rather than the glass content.

A visual examination of the definition of $0.125 \mathrm{~mm}$ lines with $0.125 \mathrm{~mm}$ spaces showed considerable variation from conductor to conductor. The S4399 and EO 6990 inks spread out so that adjacent conductor tracks were shorted out. The C5700 also spread but not to the same extent and the DP 9260, DP 9500 and ESL 8880 gave well defined lines. The T2888 seemed to contract after printing and the EMCA 3264 contracted to such an extent that the lines became discontinuous. The EMCA film was found to contain holes corresponding to the spacing of the printing mesh, confirming the very rough surface shown by Talysurf measurement.

\section{ADHESION STRENGTHS}

The adhesion of the gold conductors to the substrates was measured by pulling $0.7 \mathrm{~mm}$ diameter copper wires, soldered to $2 \mathrm{~mm}$ square conductor pads with an $80 / 20 \mathrm{Au} / \mathrm{Sn}$ solder paste. Three substrate types were used:

a) Alsimag $\operatorname{ADS} 614,96 \%$ magnesia-fluxed alumina

b) Coors AD995, 99.5\% alumina,

c) Andermann \& Ryder 974, ground to BAA 152 standard, a $97 \%$ mixed magnesia/calcia fluxed alumina The pull strengths were measured in $\mathrm{kg}$ and the results based upon the average of eight pads normalized to a $2.5 \mathrm{~mm}$ square pad are in Table I. The adhesion strength of the DP 9260 fritted conductor on both the debased aluminas was much lower than all the reactively bonded conductors. The value on the $99.5 \%$ alumina was even lower, as might be expected because there is very little substrate glass present. The adhesion strengths of all the reactively bonded conductors were lower on A \& $\mathrm{R}$ substrates.

The surface of as-received samples of the Alsimag ADS 614 96\% alumina and A \& R 974 ground substrates were examined on the SEM. The Alsimag substrate surface consisted of discrete and well defined grains as would be expected of a typical substrate used in the hybrid micro-electronics industry but the A \& R substrate surface was glassy in appearance with only a few of the grains defined. Although the ground substrate surface was flat, the microstructure as determined by Talysurf measurement was not as fine as on the Coors $99.5 \%$ alumina surface. The adhesion strengths of EMCA 3264, EO 6990 and T2888 conductors on Alsimag substrates lapped with 290 silicon carbide to remove $40 \mu \mathrm{m}$ was found to be less than on the as-received Alsimag substrates. The same gold conductors were printed and fired onto Wades substrates $(96 \%$ calcia fluxed alumina substrates) and the adhesion strengths were found to be comparable with the values on the as-received Alsimag substrates.

The adhesion strengths of the reactively bonded 
golds are lower on ground than on unground substrates. This is independent of the type of glassy phase in the substrate, and truly fritless systems based on copper and cadmium oxides are more sensitive. In all cases, ground substrates have a higher proportion of the glassy phase at the top surface than unground substrates.

The copper oxide readily dissolves in the substrate glass and this leads to a depletion of copper at the gold/substrate glass interface. The gold which relies upon the copper to form a bond to the substrate, is therefore less strongly attached and failure will occur at this interface at a lower pull strength. Examination of the areas on the ground substrates where the E06990 gold has been removed shows that the copper oxide is left behind and the underside of the removed pad is gold. The mixed bonded systems that have

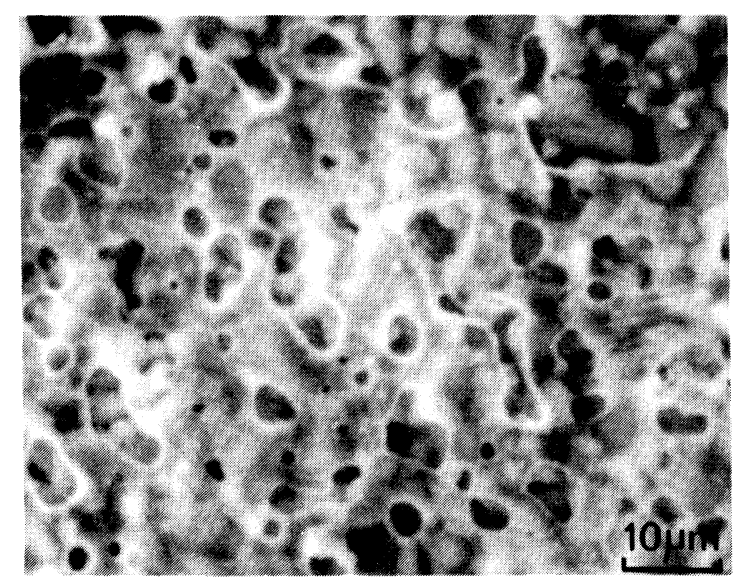

(a) SEI

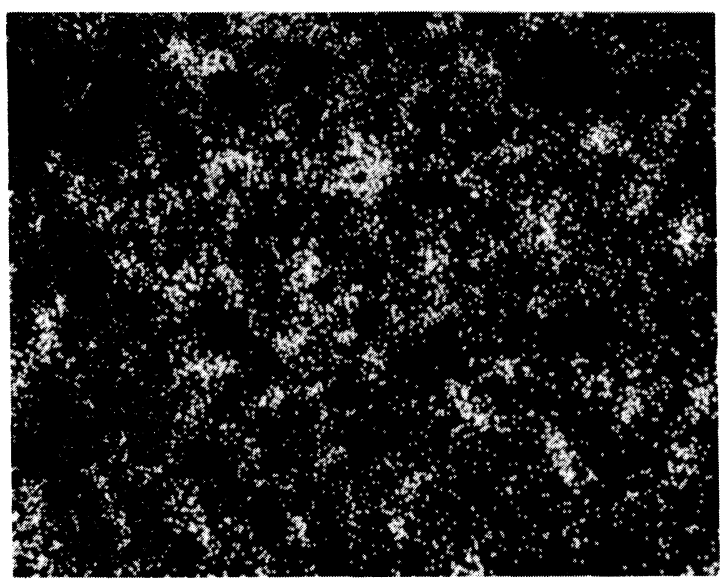

(c) Cadmium area scan glass formers (e.g. Englehard T2888 and EMCA 3264 which contain bismuth oxide) will still retain some adhesion between the conductor glass and the conductor and hence will be less sensitive to the ground substrates. The extra glass at the surface of the ground substrate is also more likely to cause increased interaction with the conductor glass in fritted conductors, possibly leading to bleed-out.

\section{EXAMINATION OF SUBSTRATES AFTER GOLD REMOVAL}

The gold from fired conductors was removed by etching in a potassium iodide-iodine solution, or mercury, and the areas of the substrate where the gold had been removed were examined by SEM. The surface of the substrates after removing T2888 and

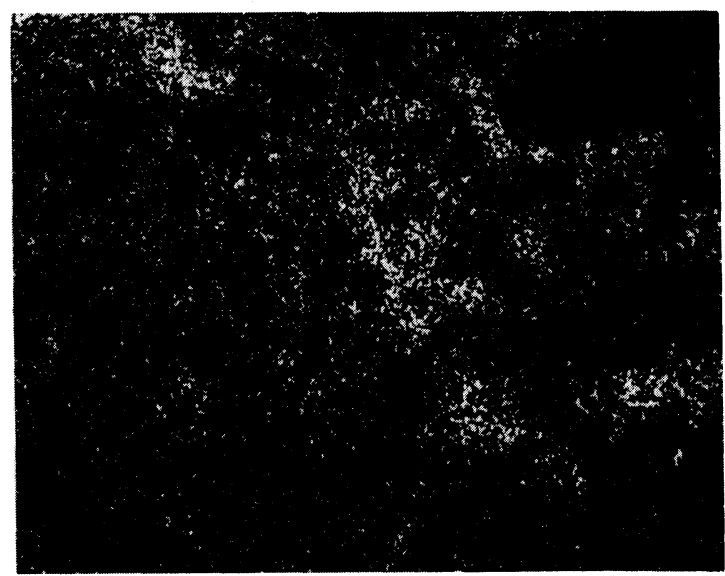

(b) Copper area scan

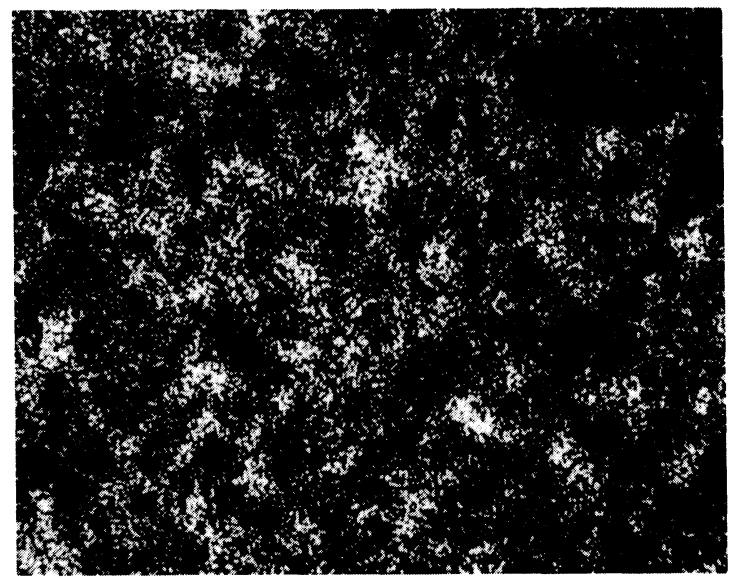

(d) Bismuth area scan

FIGURE 1 SEM/EPM analysis of alumina substrate after removal of Englehard T 2888 gold conductor. 


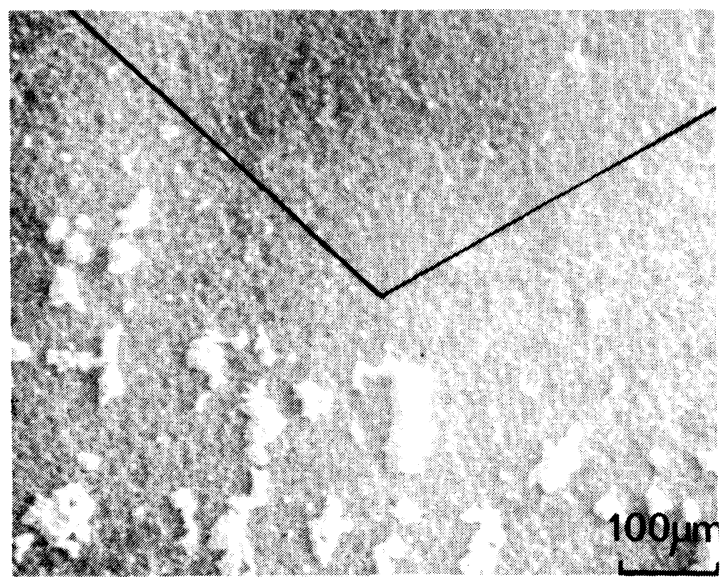

(a) SEI

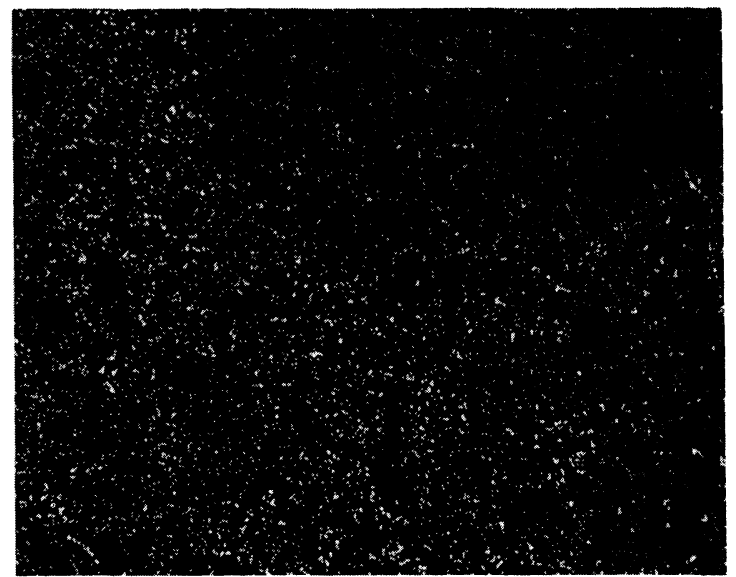

(b) Silicon area scan

FIGURE 2 SEM/EPM analysis of alumina substrate for silicon after removal of EMCA 3264 gold conductor.

EMCA 3264 golds was glassy and the major constituents were found to be copper, cadmium and bismuth, Figure 1. It was also found that there was a higher concentration of silica where the conductors had been removed than over the rest of the substrate, Figure 2, but the magnesium was uniformly distributed. The E06990 conductor had been found to contain copper oxide and this was found as discrete particles after removal of the gold conductor. There was no evidence of increased silica where the pads had been.

The behaviour of all the reactively bonded conductors was found to be similar.

In neither the EMCA 3264 nor the Englehard T2888 conductors was silicon found in the inks and yet there was evidence to suggest increased silicon concentration underneath the conductor pad. This could only be due to extraction of silica from magnesium silicate in the substrate by the metal oxides in the conductor. Hence a copper, cadmium, bismuth silicate is formed at the substrate/conductor interface and is seen as a glassy layer. The bonding of the gold is in part due to this glass via a gold-copper-oxygen bond and in part due to an aluminate formed at the substrate as in the case of the pure copper-cadmium systems. There may also be enhanced gold adhesion due to mechanical interlocking with the glass phase (as for fritted systems) which may become important with the ground substrates but is likely to be only a second order effect in general.

\section{CONCLUSIONS}

In general the properties of reactively bonded golds are comparable with the best fritted golds. Although these conductors contain over $99 \%$ gold compared with DP 9260, which is $~ 90 \%$ gold and $10 \%$ glass, the electrical conductivity is no better, suggesting that the important criterion is the number of voids present in the conductor. The choice of gold particles, in particular a mixture of gold platelets and small spheres, is a deliberate attempt to increase the density of packing and these mixtures are being used in both the fritted and reactively bonded golds.

The adhesion strength of all the conductors was found to be superior to the fritted standard. The relatively poor results for EMCA 3264 were due to the poor printing characteristics which led to a porous almost discontinuous fired film. On Andermann \& Ryder ground substrates the lower adhesion of the conductors based upon copper and cadmium oxides was found to be due to the excess substrate glass at the surfaces after grinding. Experimental analysis has shown that the copper and cadmium are alloyed to the gold and only a small proportion is present at the substrate surface. The copper was found to oxidize at the top conductor surface when the conductors were refired at $\sim 600^{\circ} \mathrm{C}$. This oxidation and the ease of dissolution in the substrate glass suggest that the copper is mobile and subsequent processing might be a problem, in particular the dissolution of copper into resistor or dielectric terminations may be a reliability hazard.

Except where stronger adhesion is required or possibly where the interface between conductor and substrate needs to be sharp (as in microwave applications) there is no dramatic improvement in character- 
istics. If no adverse interactions are found with resistors or dielectrics, the mixed bonded systems fireable at $850^{\circ} \mathrm{C}$, which have recently become available, may prove more attractive.

\section{ACKNOWLEDGEMENTS}

The authors thank STL for permission to publish this paper. The work reported has been carried out with the support of the Procurement Executive, UK Ministry of Defence, sponsored by DCVD. The STL Materials Evaluation Centre is thanked for help with the analytical work.

\section{REFERENCES}

1. L. Hailes and W. A. Crossland, Int. Elec. Pack. \& Prod., July 1972, p. 25.

2. M. V. Coleman, Radio \& Electronic Engineer, 45(3), March 1975, p. 121. 

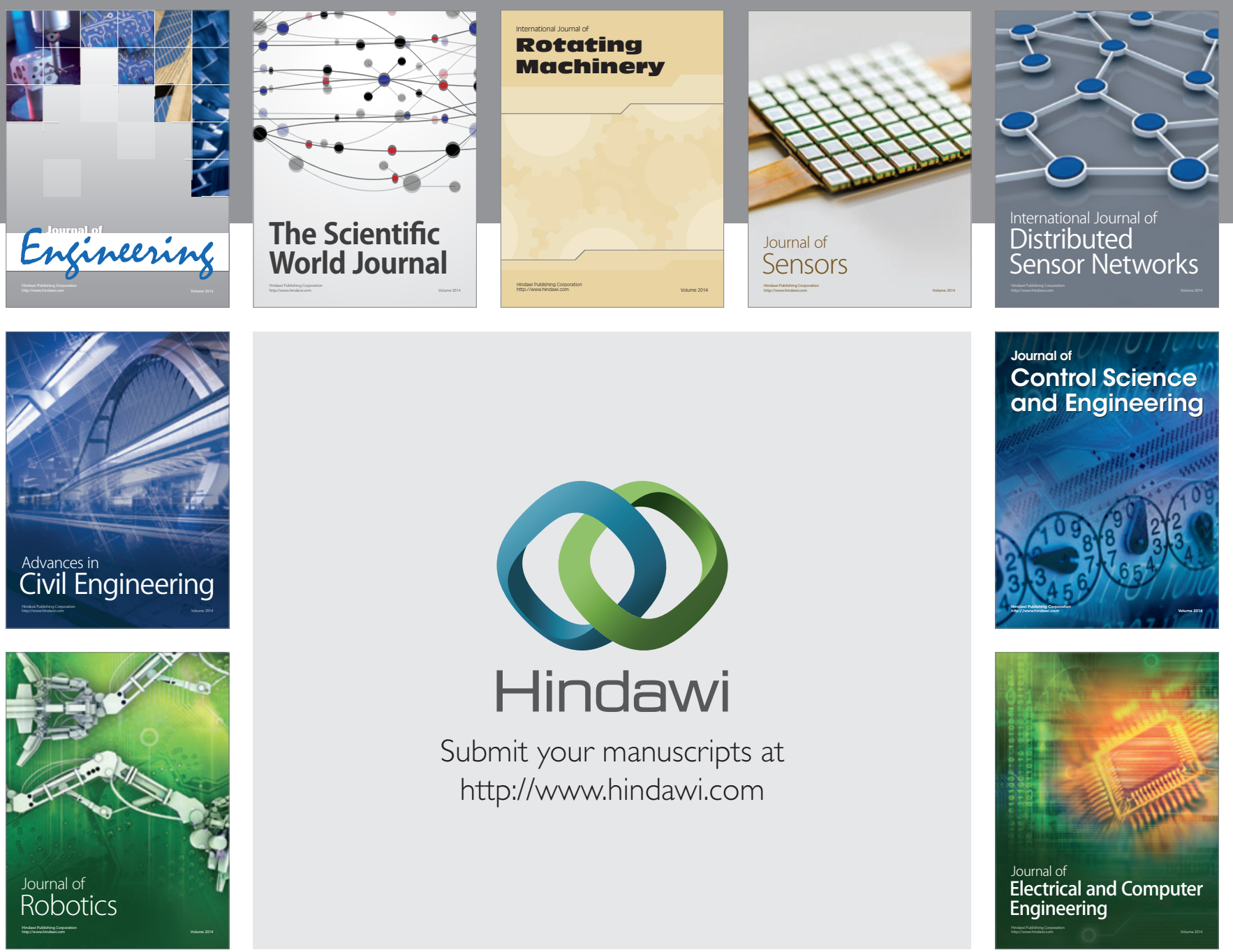

Submit your manuscripts at

http://www.hindawi.com
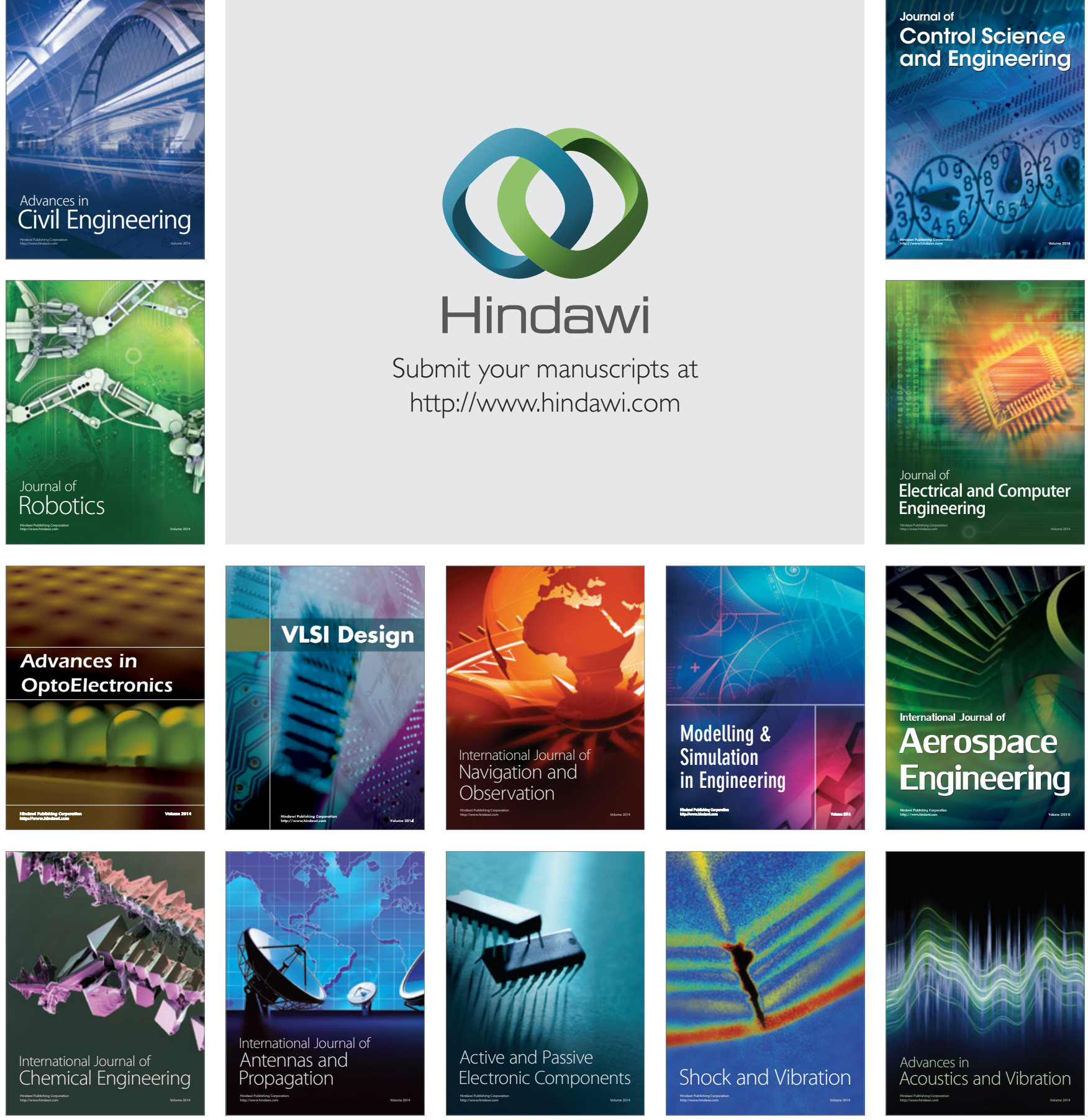